Mechatronics and Applications: An International Journal (MECHATROJ), Vol. 2, No.1

\title{
FABRication OF Di-WHEEl By COMPUTATIONAL AND EXPERIMENTAL APPROACH
}

\author{
Abhishek Chouhan ${ }^{1}$, Adarsh Prajapati ${ }^{1}$, Balashish Dubolia ${ }^{1}$, Dayanand Kumar \\ Gupta $^{1}$, Deepesh Kumar Ratra ${ }^{1}$, Shivam Singh ${ }^{1}$, Vivek Shukla ${ }^{2}$ \\ ${ }^{1}$ Scholars, Department of Mechanical Engineering, Malwa Institute of Science \& \\ Technology, Indore. \\ ${ }^{2}$ Assistant Professor, Department of Mechanical Engineering, Malwa Institute of Science \\ \& Technology, Indore.
}

\begin{abstract}
The paper here shows the work performed by our team on a fabrication of Di-wheel, which we provide a name "METO" stands for a combination of Mechanical and Electrical device for our design. We have focused here to redefine and replace the basic mode of transportation made for the national parks and tourism sectors by using more comfortable, eco-friendly and a fun loving mode of transportation. The main challenge for designing the component is to provide actual stability with exact degree of freedom. The working condition of the product for moving it in forward direction, reverse direction and to provide better rotations was also a difficult task to be done. By studding these challenges and working factors the Diwheel provides a perfect platform for the implementation of control strategies to improve the ride of the vehicle. We put our full effort here to provide a new way of ride for the amusement parks that can help people to enjoy the better standard of living. Our design gives a successful and efficient outcome as noted, so here we provide knowledge of our whole project by using proper simulations and results.
\end{abstract}

\section{KEYWORDS}

Standard specifications, Design, Mathematics, Creo, ANSYS Workbench, METO (Mechanical and Electric Di-wheel), and Machines

\section{NOMENCLATURE}

\begin{tabular}{|c|c|c|}
\hline S. No & Notation & Specification \\
\hline 1. & UCFL & Specification of Bearing \\
\hline 2. & 6202 & Bearing Specification \\
\hline 3. & $\mathrm{D}$ & Length for maximum ends of bearings \\
\hline 4. & $\mathrm{~B}$ & Bearing width \\
\hline 5. & $\mathrm{~d} 1$ & Inner hub distance \\
\hline 6. & $\mathrm{D} 2$ & Inner distance of outer hub \\
\hline 7. & $\mathrm{R} 1,2$ & Radial curves of Inside hub \\
\hline 8. & MY1020Z600W36V3200 RPM & Motor Specification \\
\hline 9. & $\mathrm{~V}$ & Voltage \\
\hline 10. & $\mathrm{I}$ & Current \\
\hline 11. & $\mathrm{P}$ & Power \\
\hline 12. & $\mathrm{~N}$ & Speed \\
\hline 13. & $\tau$ & Torque \\
\hline 14. & $\omega$ & Angular Speed \\
\hline 15. & $\eta$ & Efficiency \\
\hline
\end{tabular}


Mechatronics and Applications: An International Journal (MECHATROJ), Vol. 2, No.1

\begin{tabular}{|l|c|c|}
\hline 16. & $\mathrm{~T}$ & Time \\
\hline 17. & $\mathrm{~A}$ & Acceleration \\
\hline 18. & $\mathrm{v}$ & Outer velocity \\
\hline 19. & $\mathrm{u}$ & Inner velocity \\
\hline 20. & $\mathrm{~F}$ & Force \\
\hline 21. & $\mathrm{~m}$ & Mass \\
\hline 22. & $\mathrm{C}$ & Basic dynamic load rating \\
\hline 23. & $\mathrm{C}_{0}$ & Basic static load rating \\
\hline 24. & $\mathrm{P}_{\mathrm{u}}$ & Fatigue load limit \\
\hline 25. & $\mathrm{Nr}$ & Reference speed \\
\hline 26. & $\mathrm{~N}$ & Limiting speed \\
\hline 27. & $\mathrm{k}_{\mathrm{r}}$ & Calculation factor \\
\hline 28. & $\mathrm{f}_{0}$ & Calculation factor \\
\hline
\end{tabular}

\section{INTRODUCTION}

Di-wheel was not a new concept with patents in existence from as early as 1947 (Vereycken, 1947). Despite over 60 years of existence Di-wheels have not been a commercial success, primarily due to its degree of freedom problem [1]. A Di-wheel is defines as the two wheeled vehicle in which an inner space frame suspended by various wheels to get the support from main outer wheel that rotates about an axis. Di-wheels are designed by changing various components from past decay to gain its stability in efficient manner. The axial alignment of the wheels also means that a Di-wheel can rotate without translation allowing for fast direction changes, unlike bicycles and motorcycles which suffer from non-harmonic constraints. Often supported by idler wheels, the inner frame drives the two outer wheels, where torque is provide a shift in the centre of gravity of the inner frame to allow both forward and backward motion.

As we discuss above that we provide the name of our design "METO" a concept of combined mechanical and electrical in which the outer wheels are independently powered by two motors powering the vehicle to yaw. Although the inner frame of a Di wheel is used to initiate motion by way of displacement, unwanted movement back and forth can affect the comfort of the driver and also the ability to safely maneuver the vehicle. Oscillation of the inner frame put with respect of centre of gravity. This is easily understood if one considers the inner frame to act as liquid when the vehicle is accelerated. The inner frame is completely within the bounds of the two large outer wheels enabling the vehicle to move forward, backward and rotate on the spot. The beauty of the Di-wheel is that the way the inner frame is suspended between the outer wheels allows it to freely rotate within the outer wheels, which is unique to this type of vehicle.

EDWARD [2] 2010: - The revolutionary design was created first by University of Adelaide in Australia in 2010 which known as the first electric mode of transportation.

EDWARD [2] 2011: - The design was being revised again and some corrections were being made in terms of chain cover, slippery control, slosh control etc.

Again [3] University of Adelaide compares the experimental results with the simulation work which shows some effectiveness of design in their research.

Di-wheel produced for human use constructed and designed by Ernest Fraquelli in 1935 and finally patented in 1947 , there have been a number of attempts to utilize the unique dynamics that the Di-wheel has to overcome. Sadly, partly due to its nature, Di-wheels have never been commercially successful. In order to prevent the mistakes of previous Di-wheel designs are view of similar systems in existence is presented below, along with a review of the dynamics of similar systems and the corresponding control techniques [3]. 


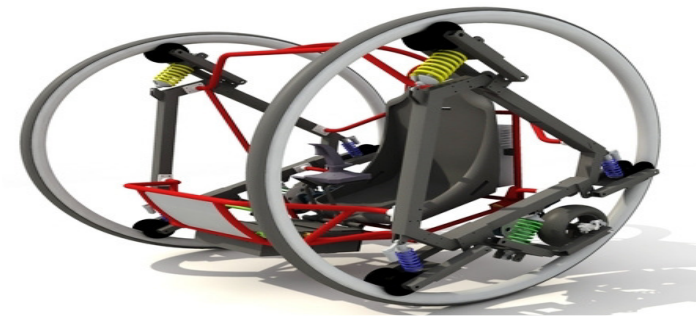

Figure 1 IC Engine Di-wheel EDWARD [3]

All previous designs of Di-wheels present a similar structure including two large outer wheels, an inner frame and a means of propulsion. The early Di-wheels, including the 1947 Belgian patented design, seen in Figure 1, were generally powered by means of combustion engines (Vereycken, 1947).

The diameter of the outer wheel and the contact that it makes with the ground affect the dynamics of the Di-wheel system. Due to the unique design and size of the outer wheels, there have been difficulties in producing conventional pneumatic based wheels suitable for use on a Di-wheel. As with the outer wheel, construction of the tire of the Di-wheel is difficult to produce, and hence custom designs are common.

Explanation of all control techniques of operating a complicated design was also given by University of Adelaide [4].

Generally our METO has been designed to fulfill the optimum standards of living of peoples in the major sectors of tourism i.e.

$>$ National Parks

$>$ Amusement Parks

$>$ Theme Parks

$>$ Compact Automobiles of the Future

\section{Parts Description}

Now here in this section we are continuing to present our work by taking an experimental simulation. As known designing a product needs some back ground study so we are here explains all important parts used for designing our model [5].

Table 2.1 Described parts

\begin{tabular}{|c|c|}
\hline S. No & Part Name \\
\hline 1. & Drive wheel \\
\hline 2. & Idler wheel \\
\hline 3. & Chassis design \\
\hline $\mathbf{4 .}$ & Outer wheel \\
\hline $\mathbf{5 .}$ & Shaft carrier \\
\hline $\mathbf{6 .}$ & Bearings \\
\hline $\mathbf{7 .}$ & Shaft \\
\hline $\mathbf{8 .}$ & Nuts and bolts \\
\hline $\mathbf{9 .}$ & Battery \\
\hline $\mathbf{1 0 .}$ & Chain and Sprocket \\
\hline
\end{tabular}




\section{$>$ Drive Wheel}

As the outer wheels to be driven from the inner frame, a drive wheel is used. The drive wheel which aims to providing a continual contact with the outer wheel to ensure stable and predictable driving performance. Continual contact of the drive wheel and the outer wheel is vital for reliable control. Table 1 shows the specification of Drive wheel used in our work also shown clearly in Figure 2 .

Table1 Drive wheel Specification

\begin{tabular}{|c|c|c|}
\hline S. No & Specifications & Values \\
\hline 1. & Outer diameter & $254 \mathrm{~mm}$ \\
\hline 2. & Inner diameter & $203.2 \mathrm{~mm}$ \\
\hline 3. & Outer dia. Thickness & $10 \mathrm{~mm}$ \\
\hline 4. & Inner dia. Thickness & $50 \mathrm{~mm}$ \\
\hline
\end{tabular}

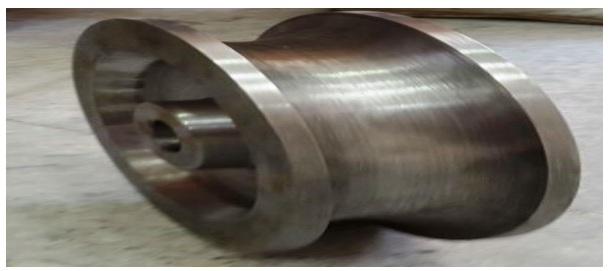

Figure 2 Drive wheel

\section{Idler wheels}

In corporate within the inner frame of the Di-wheel there are four idler assemblies located approximately equidistant from the axis of rotation of the outer wheels. Figures 29 of main assembly part had shown it clearly. We focus here in the three regions of the idler wheel during the designing of idler wheels. Region A is the contact region, Region B is the curved profile resulting in a decreased wedge effect. Region $\mathrm{C}$ is the idler walls used to prevent derailing. Inner frame stays within the outer wheels. The idlers are used to Centre the frame within the outer wheels, allowing it to roll freely. There are three main areas of focus with the development of the idler wheels:

- The contact region

- The curved profile in the middle of the idler

- The walls of the idler

Table 2 shows the specification of idler wheel with actual Figure 3.

Table 2 Idler Wheel Specifications

\begin{tabular}{|c|c|c|}
\hline S. No & Specifications & Values \\
\hline 1. & Outer diameter & $100 \mathrm{~mm}$ \\
\hline 2. & Inner diameter & $80 \mathrm{~mm}$ \\
\hline 3. & Thickness of each outer diameter & $5 \mathrm{~mm}$ \\
\hline 4. & Thickness inner diameter & $40 \mathrm{~mm}$ \\
\hline 5. & Angle(inner to outer) & 30 degree \\
\hline
\end{tabular}


Mechatronics and Applications: An International Journal (MECHATROJ), Vol. 2, No.1

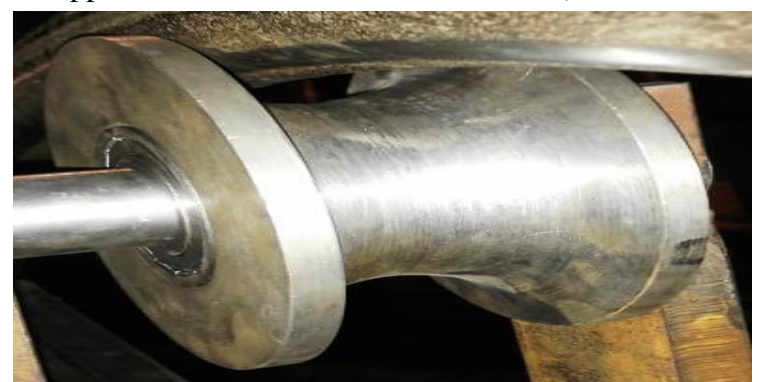

Figure 3 Idler Wheels

\section{Outer wheel}

A Di-wheel assembled with two large parallel outer wheels that having the same axis of rotation. These wheels completely encompass an inner frame which allows the driver to be positioned safely within the outer wheels. In our design named "METO" two large outer wheels rolled from F45 tubing with a rubber strip placed on the outside edge of the wheels for added grip and comfort during operation. The advantage of this design is a high strength to weight ratio, and easy location of the inner frame during assembly. The outer wheels were kept from the previous year's design, as they were deemed to be highly effective as shown in Table 3 and Figure 4.

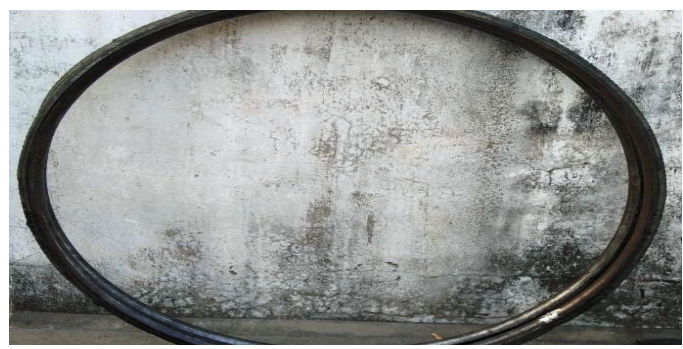

Figure 4 Outer Wheels

Table 3 Outer Wheel Specifications

\begin{tabular}{|c|c|c|}
\hline S. No & Specification & Value \\
\hline 1. & Diameter of outer wheels & $1500 \mathrm{~mm}$ \\
\hline
\end{tabular}

\section{Shaft and shaft carrier}

The shaft was made up of cast iron selected excellent in elastic properties in order to bear high impact load easily without failure. The rigidity of shaft would be high during low load conditions. The shaft was made for two conditions

- Heavy load conditions (driver shaft)

- Low load conditions (steady shaft)

The cross section of shaft was different for two phenomena which are as follows:

1. Shaft A cross-sections $-70 \mathrm{~mm} \times 16 \mathrm{~mm}$

2. Shaft B cross-sections $-65 \mathrm{~mm} \times 16 \mathrm{~mm}$

The shaft carrier was designed on the basis of weight of driver wheel and chassis. It was also designed on the basis of force (torque) generation generated by driver wheel on outer wheel for rotation. So we decided to take $16 \mathrm{~mm}$ thick iron bars. The iron bars we chose were excellent in elasticity i.e. it can be molded easily. The cross section was selected on the basis of bearing id and with minimum allowance for the shaft. 
Mechatronics and Applications: An International Journal (MECHATROJ), Vol. 2, No.1

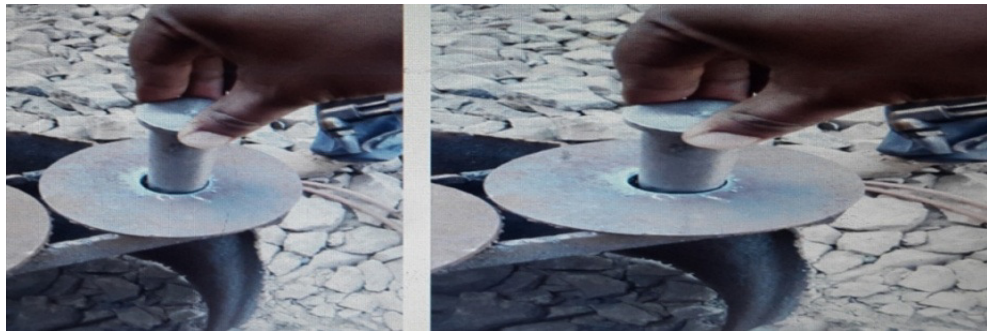

Figure 5 Shafts

\section{Bearing}

The bearing we used in METO was divided in two categories depending on load conditions

1. Heavy rpm (load) condition

2. Low rpm (load) condition.

On such variable condition, we came up with our detailed studies and selected two bearing:-

1. FL bearing (heavy load conditions)

2. 6206 (low load conditions)

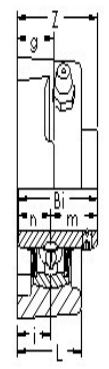

Figure 6.1 FL Bearing 2D Draft [10]

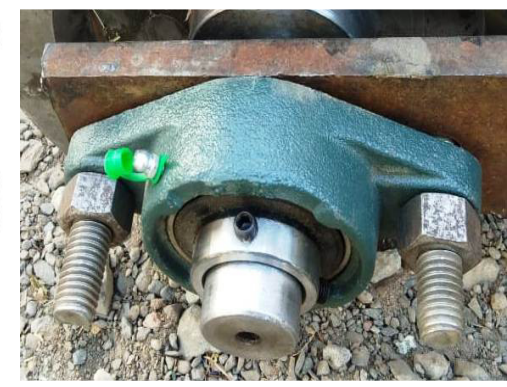

Figure 6.2 Actual placed Bearing

Figure 6 Bearings

Table 4 Specification chart of FL bearing

\begin{tabular}{|c|c|c|}
\hline Bearing Type & Cast Iron Housing & Unit \\
\hline Dynamic load rating & 14,022 & $\mathrm{~N}$ \\
\hline Static load rating & 7,843 & $\mathrm{~N}$ \\
\hline Housing width & 68.000 & $\mathrm{~mm}$ \\
\hline Mounting hole centre to centre & 99.000 & $\mathrm{~mm}$ \\
\hline Housing length & 130.000 & $\mathrm{~mm}$ \\
\hline Housing base thickness & 13.000 & $\mathrm{~mm}$ \\
\hline Bearing inner race width & 34.000 & $\mathrm{~mm}$ \\
\hline Bearing inner race width short side & 14.000 & $\mathrm{~mm}$ \\
\hline Bearing inner race width extended side & 20.000 & $\mathrm{~mm}$ \\
\hline
\end{tabular}

\section{Bearing}

Deep groove ball bearings are particularly versatile. They are suitable for high and very high speeds, accommodate radial and axial loads in both directions and require little maintenance. 
Mechatronics and Applications: An International Journal (MECHATROJ), Vol. 2, No.1

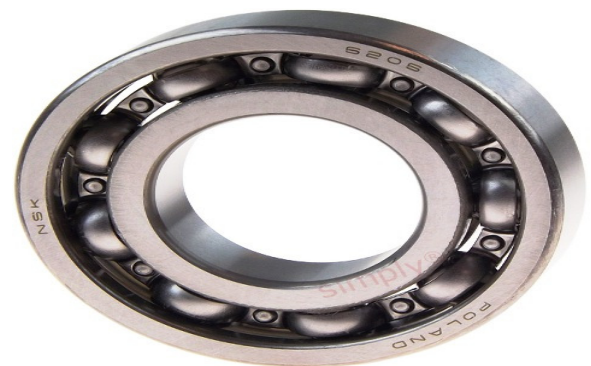

Figure 76206 Bearing [7]

Table 5 Dimensions of 6206 Bearing [7]

\begin{tabular}{|c|c|c|c|c|}
\hline S. No & Specifications & Equality & Value & Units \\
\hline 1. & $\mathrm{D}$ & & 30 & $\mathrm{Mm}$ \\
\hline 2. & $\mathrm{D}$ & & 62 & $\mathrm{Mm}$ \\
\hline 3. & $\mathrm{~B}$ & & 16 & $\mathrm{Mm}$ \\
\hline 4. & $\mathrm{~d}_{1}$ & $\approx$ & 40.36 & $\mathrm{Mm}$ \\
\hline 5. & $\mathrm{D}_{2}$ & $\approx$ & 54.06 & $\mathrm{Mm}$ \\
\hline 6 & $\mathrm{r}_{1,2}$ & $\min$. & 1 & $\mathrm{Mm}$ \\
\hline
\end{tabular}

Table 6 Specification charts of 6206 bearing [7]

\begin{tabular}{|c|c|c|c|c|}
\hline S. No & Specification & Symbol & Value & Units \\
\hline 1. & Basic dynamic load rating & $\mathrm{C}$ & 20.3 & $\mathrm{KN}$ \\
\hline 2. & Basic static load rating & $\mathrm{C}_{0}$ & 11.2 & $\mathrm{KN}$ \\
\hline 3. & Fatigue load limit & $\mathrm{P}_{\mathrm{u}}$ & 0.475 & $\mathrm{KN}$ \\
\hline 4. & Reference speed & & 24000 & $\mathrm{RPM}$ \\
\hline 5. & Limiting speed & & 15000 & $\mathrm{RPM}$ \\
\hline 6. & Calculation factor & $\mathrm{k}_{\mathrm{f}}$ & 0.025 & \\
\hline 7. & Calculation factor & $\mathrm{f}_{0}$ & 14 & \\
\hline
\end{tabular}

\section{Electric motor and Battery system}

The electric motor was selected on the basis of torque calculations. The selection of motor is done by analyzing the whole working parameters. By studding working weight, torque, motions, power etc, we found that electric motor of MY1020Z 600W 36V 3200RPM DC motor suits best for us. Table 7 shows various specifications of the motor with clear view in Figure 8. 
Mechatronics and Applications: An International Journal (MECHATROJ), Vol. 2, No.1

Table 7 Motor Specifications [8]

\begin{tabular}{|c|c|c|}
\hline S. No & Specifications & Values \\
\hline 1 & Model & MY 1020Z2 \\
\hline 2 & Rated output power & $600 \mathrm{~W}$ \\
\hline 3 & Rated voltage & $36 \mathrm{~V}$ \\
\hline 4 & No Load speed & $3700 \mathrm{RPM}$ \\
\hline 5 & Rated speed & $3200 \mathrm{RPM}$ \\
\hline 6 & No Load Current & $2.5 \mathrm{~A}$ \\
\hline 7 & Full Load Current & $21.40 \mathrm{~A}$ \\
\hline 8 & Rated Torque & $1.80 \mathrm{Nm}$. \\
\hline 9 & Efficiency & $78 \%$ \\
\hline 10 & Gear Ratio & $1: 6.67$ \\
\hline 11 & Weight & $5.438 \mathrm{~kg}$ \\
\hline
\end{tabular}

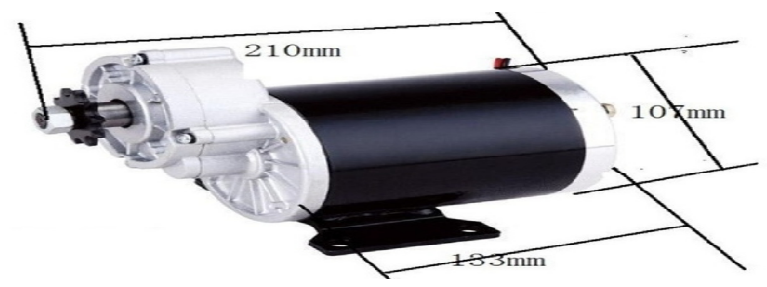

Figure 8 Electric motor MY1020Z 600W 36V 3200RPM [9]

Here to operate and control this specification of motor in our system we provide $12 \mathrm{~V} 7 \mathrm{~A}$ battery for power generation which gives us an output power of 360 Watts.

\section{Controller}

It is a chip or expansion card that interfaces with a peripheral device. In the same manner microcontroller is the small computer on a single integrated circuit. Now the Game controller is an input device used for playing video games. Control of continuously operating dynamical systems in engineered processes and machines. The type of controller used in our working project can control power up to 60 watts for smooth running of motor. Basically such high torque generating motors needs a controller to control the device for normal and fluent operations.

\section{Chain and sprocket}

This mechanism of chain and sprocket in our design is used for power transmission from motor to wheel. As in our design the distance between motor and wheel must be less so we used a 42 teeth and 23 teeth sprocket with chain of \#409. The chain we used having a bearing load capacity of $1600 \mathrm{~N}$. The sprocket was designed on the basis of law of mechanics. The sprocket has a pitch of $3 / 4^{\text {th }}$.

\section{Present Aim And Work}

Here in this portion of this paper we are going to present the actual need of our work with respect to the problems arises in previous designs. The section here divided into two categories the problem and its solution which comes by doing various researches on the work of previous researchers.

\section{$>$ Problem Domain}

From the history of Di-wheel we came to know that on previous research and development the Di-wheel was made like 
Mechatronics and Applications: An International Journal (MECHATROJ), Vol. 2, No.1

1. The chassis with heavy amount of complicated joints

2. Arrangement and quantity of suspension system

3. We also noted that previous designs contains less torque

4. The motor which used in the previous design were not properly specified type

5. The design of previous Di-wheels also have controlling unit problem

\section{Solution Domain}

After study and analyze the studies of previous theories, we put our work with respect to these problems and consider them as our main modifications. In our design of Di-wheel we work on all these problems and successfully run our system efficiently. The major points in which we show our work are

1. A very new type design and model of working Di-wheel

2. Chassis joints and their placements were modified

3. We are able to generate more torque in working as compare to others

4. We also provide updated controlling units

5. We eliminate the placement of suspension system in our design and tried to provide natural comfort

6. We also got success in cost reduction factor

\section{Computational Designing And Simulation}

After doing all our research we move towards the computations methods in which we design all main parts separately and also analyze them. So for designing of components we used Creo software and ANSYS workbench is used for analysis. All separate figures with specified data present in this section provides overall computational work done by us.

\section{Chassis Design}

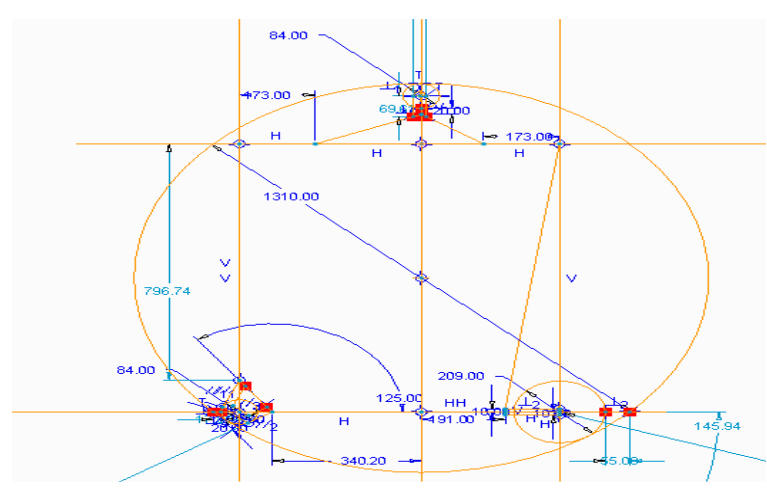

Figure 9 Chassis full assembly Design 
Mechatronics and Applications: An International Journal (MECHATROJ), Vol. 2, No.1

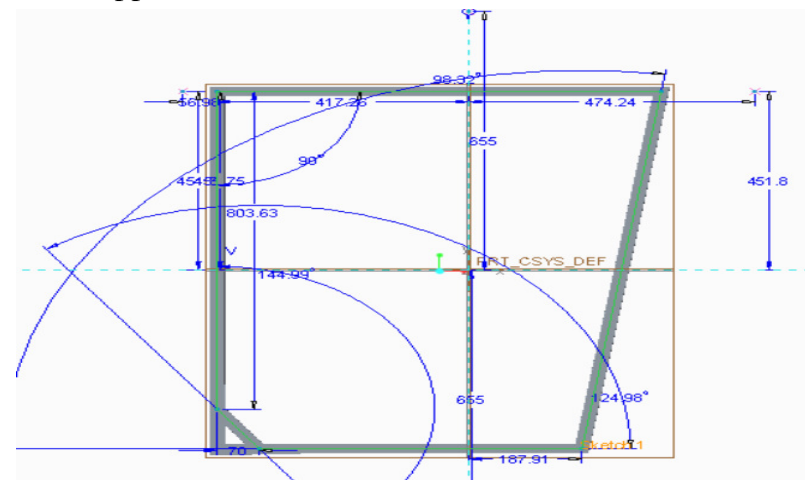

Figure 10 Chassis Structural Design

\section{Drive Wheel with Specification}

Table 8 Di-wheel Design

\begin{tabular}{|c|c|c|}
\hline S. No & Specifications & Values \\
\hline 1. & Outer diameter Thickness & $10 \mathrm{~mm}$ \\
\hline 2. & Inner diameter Thickness & $50 \mathrm{~mm}$ \\
\hline 3. & Outer diameter & $254 \mathrm{~mm}$ \\
\hline 4. & Inner diameter & $203.2 \mathrm{~mm}$ \\
\hline
\end{tabular}

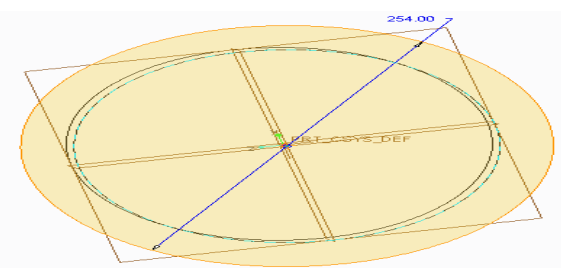

(A)

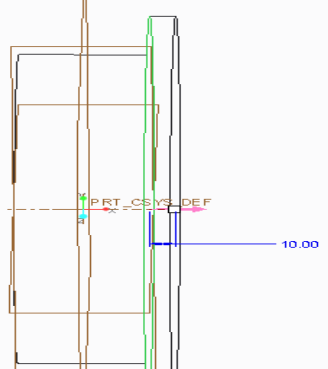

(B)

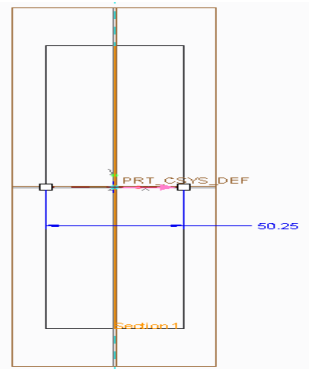

(C)

Figure 11 Drive Wheel (A) Top view, (B) Front view, and (C) Side view Idler Wheel Design Specifications

Table 9 Idler Wheel Design

\begin{tabular}{|c|c|c|}
\hline S. No & Specifications & Values \\
\hline 1. & Outer diameter & $100 \mathrm{~mm}$ \\
\hline 2. & Inner diameter & $80 \mathrm{~mm}$ \\
\hline 3. & Thickness of each outer dia. & $5 \mathrm{~mm}$ \\
\hline 4. & Thickness inner dia. & $40 \mathrm{~mm}$ \\
\hline 5. & Angle(inner to outer) & 30 degree \\
\hline
\end{tabular}


Mechatronics and Applications: An International Journal (MECHATROJ), Vol. 2, No.1

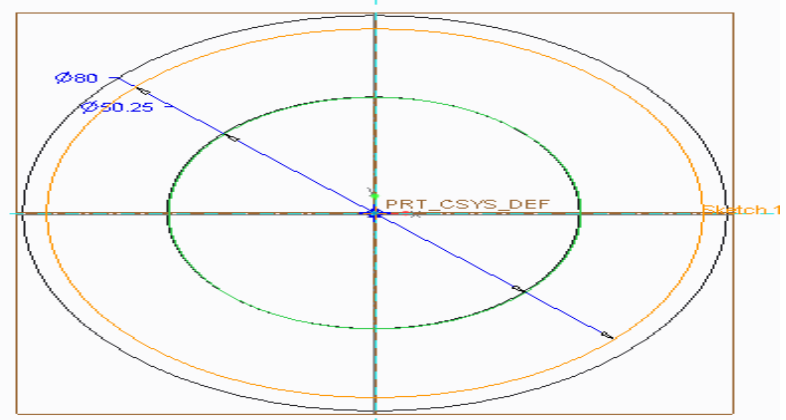

Figure 12 Idler Wheel

\section{Outer Wheel Design Specification}

Table 10 Outer wheel Design

\begin{tabular}{|c|c|c|}
\hline S. No & Specification & Values \\
\hline 1. & Outer diameter & $1370 \mathrm{~mm}$ \\
\hline 2. & Inner diameter & $131 \mathrm{~mm}$ \\
\hline 3. & Thickness & $13 \mathrm{~mm}$ \\
\hline
\end{tabular}

\section{Bearing Design Specification}

Table 11 Bearing Design

\begin{tabular}{|c|l|l|}
\hline S. No & Specification & Values \\
\hline 1. & Outer diameter & $50 \mathrm{~mm}$ \\
\hline 2. & Inner diameter & $30 \mathrm{~mm}$ \\
\hline 3. & Thickness & $15 \mathrm{~mm}$ \\
\hline
\end{tabular}

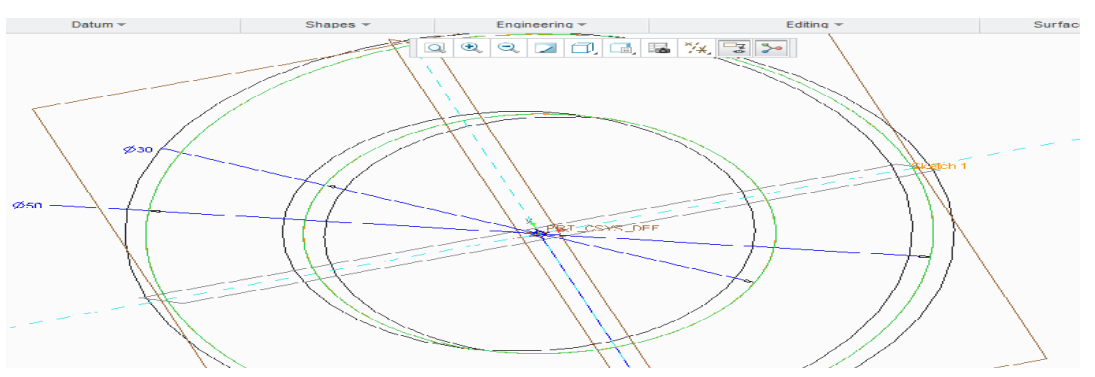

Figure 13 Bearing

\subsection{Dimensional Computer Drafting}

The section here we are presenting the diagrammatic view of designing our parts with respect to full assembly from figure 14 to Figure 22. 
Mechatronics and Applications: An International Journal (MECHATROJ), Vol. 2, No.1

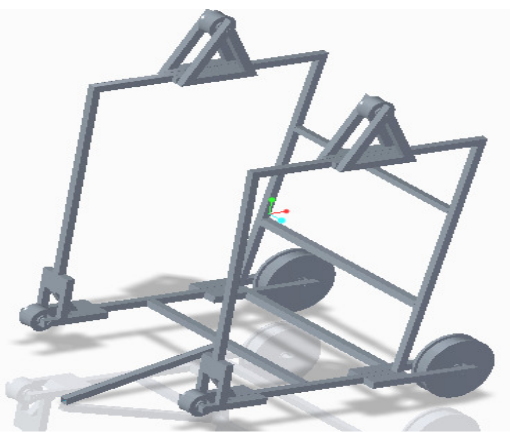

Figure 14 Chassis Body with inner wheels assembled

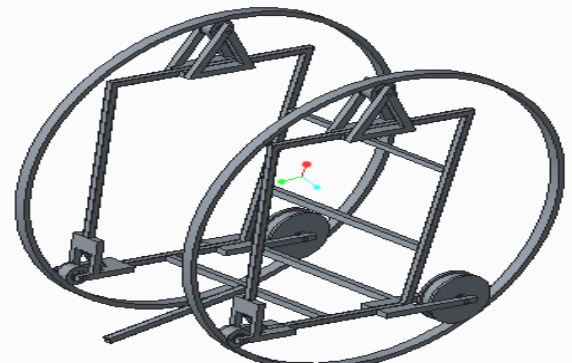

Figure 15 Chassis Body with outer wheels assembled

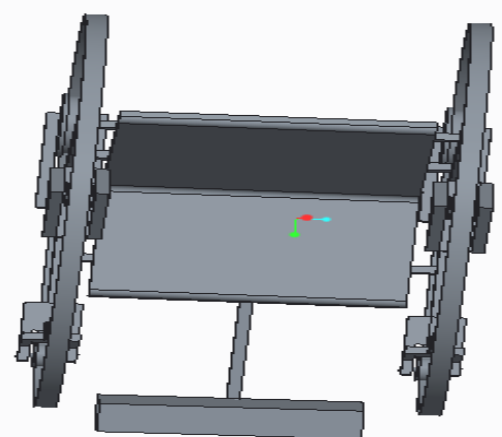

Figure 16 Chassis full Assembly (Top view)

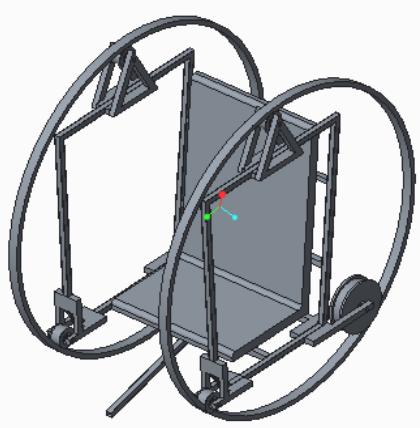

Figure 17 Chassis full assembly (Isometric View) 
Mechatronics and Applications: An International Journal (MECHATROJ), Vol. 2, No.1

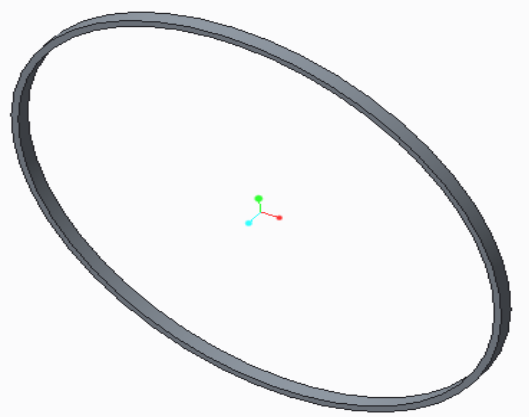

Figure 18 Outer Wheel

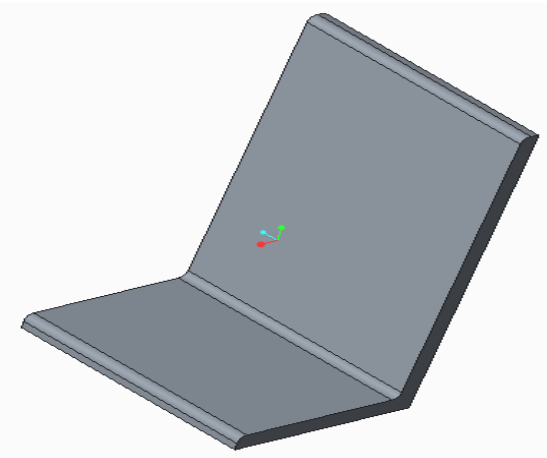

Figure 19 Seat

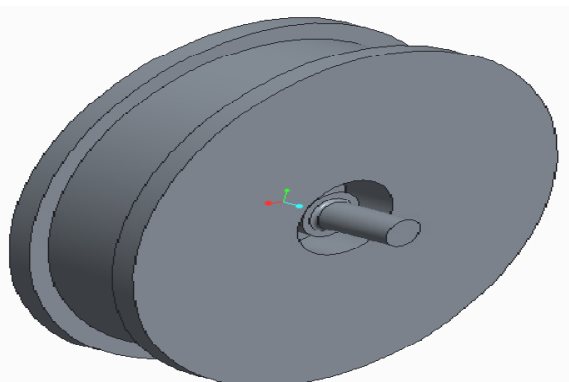

Figure 20 Dive Wheel

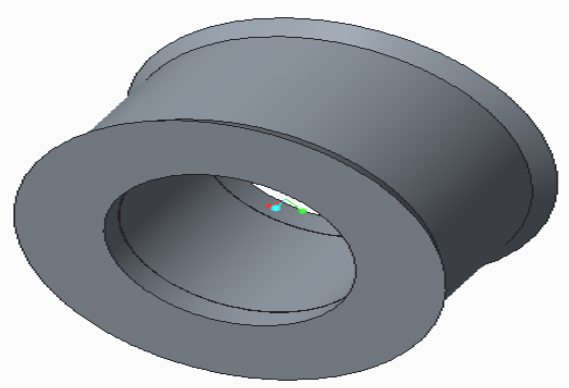

Figure 21 Idler Wheel 
Mechatronics and Applications: An International Journal (MECHATROJ), Vol. 2, No.1

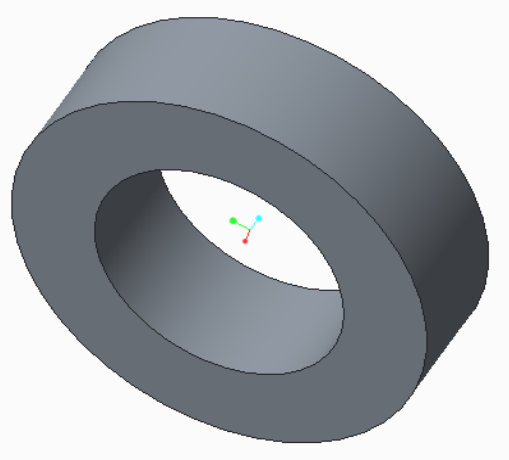

Figure 22 Bearing

\section{* Computational analysis and report of ANSYS}

$>$ ANSYS report on Chassis Frame

Table 4.5 Chassis Ansys Notations

\begin{tabular}{|c|c|c|}
\hline S. No & Specification & Values \\
\hline 1. & Force & $2000 \mathrm{~N}$ \\
\hline 2. & Direction Components & Vector \\
\hline 3. & Load Impact & Front \\
\hline 4. & Analysis & Equivalent Stress \\
\hline 5. & Mass & $17.61 \mathrm{~kg}$ \\
\hline 6. & Volume & 2.25 le $+006 \mathrm{~mm}^{2}$ \\
\hline 7. & Centroid X & $83.109 \mathrm{~mm}$ \\
\hline 8. & Centroid Y & $-180.63 \mathrm{~mm}$ \\
\hline 9. & Centroid Z & $362.5 \mathrm{~mm}$ \\
\hline 10. & Minimum Stress & $5.6328 \mathrm{e}-009 \mathrm{MPa}$ \\
\hline 11. & Maximum Stress & $98.441 \mathrm{MPa}$ \\
\hline
\end{tabular}

On the basis of above figure 23 we conclude that the analysis of chassis body is to be fixed from 5 Faces from back side as fixed support and then we apply a force of $2000 \mathrm{~N}$ from the front of the chassis.

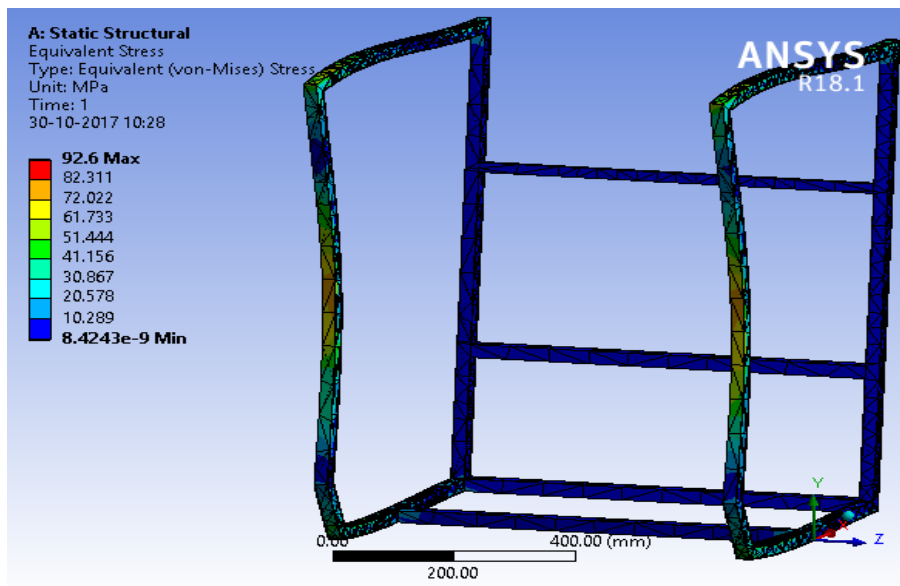

Figure 23 Analyses of Chassis 
Mechatronics and Applications: An International Journal (MECHATROJ), Vol. 2, No.1

ANSYS report on Idler Wheel Assembly

Table 12 Idler Wheel Ansys Notations

\begin{tabular}{|c|l|l|}
\hline S. No & Specification & Values \\
\hline 1. & Force & $2000 \mathrm{~N}$ \\
\hline 2. & Direction Components & Vector \\
\hline 3. & Load Impact & Top \\
\hline 4. & Analysis & Total Deformation \\
\hline 5. & Mass & $17.61 \mathrm{~kg}$ \\
\hline
\end{tabular}

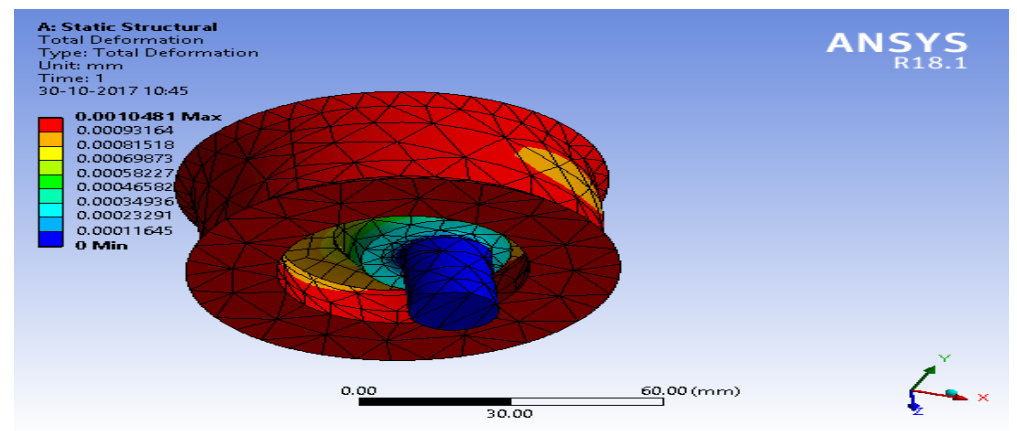

Figure 24 Analyses of Idler wheel assembly

As shown in Figure 24 of Idler Wheel Assembly we fix the Idler wheel by 4 faces as fixed support and then applying a force of $2000 \mathrm{~N}$ from the top.

\section{ANSYS report on Frame Material}

Table 13 Frame Ansys Notations

\begin{tabular}{|c|l|l|}
\hline S. No & Specification & Values \\
\hline 1. & Force & $2000 \mathrm{~N}$ \\
\hline 2. & Direction Components & Vector \\
\hline 3. & Load Impact & Top \\
\hline 4. & Analysis & Equivalent Stress \\
\hline
\end{tabular}

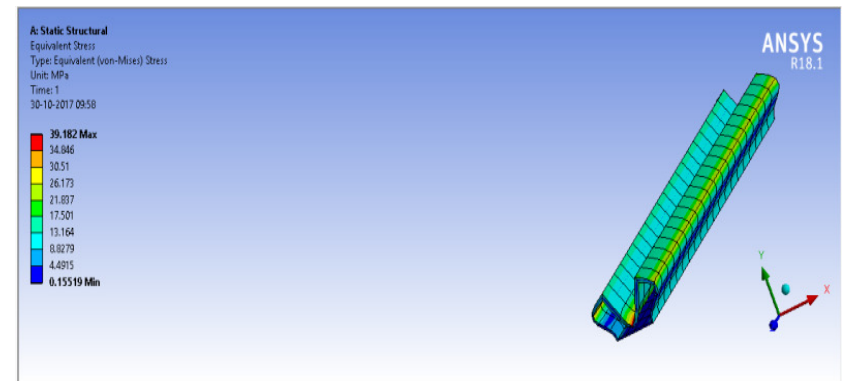

Figure 25 Frame Materials analyses on Ansys

Figure 25 shows the maximum and minimum values of analyses in which the Frame material is fixed by one face as fixed support and then applying a force of $2000 \mathrm{~N}$ from the opposite side.

\section{ANSYS report on Outer Wheels}


Mechatronics and Applications: An International Journal (MECHATROJ), Vol. 2, No.1

Table 14 Outer wheel Ansys Notations

\begin{tabular}{|c|c|c|}
\hline S. No & Specifications & Values \\
\hline 1. & Force & $2000 \mathrm{~N}$ \\
\hline 2. & Direction Components & Vector \\
\hline 3. & Load Impact & Top \\
\hline 4. & Analysis & $27.25 \mathrm{~kg}$ \\
\hline 5. & Mass & $2.6853 \mathrm{e}-014 \mathrm{~mm}$ \\
\hline 6. & Centroid X & $0 \mathrm{~mm}$ \\
\hline 7. & Centroid Y & $-9.3578 \mathrm{e}-015 \mathrm{~mm}$ \\
\hline 8. & Centroid Z & $5.9911 \mathrm{e}-003 \mathrm{MPa}$ \\
\hline 9. & Minimum Stress & $0.39088 \mathrm{MPa}$ \\
\hline 10. & Maximum Stress & \\
\hline
\end{tabular}

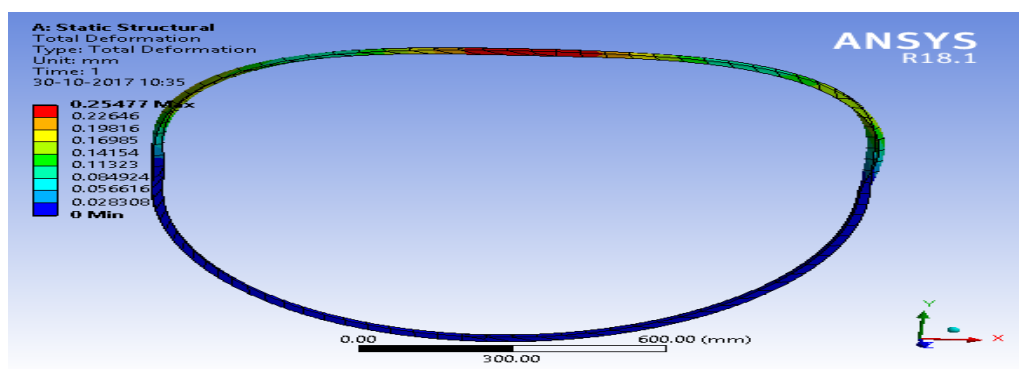

Figure 26 Analyses of Outer Wheel

The above figure 26 represents Outer wheel which is fixed from the bottom as a fixed support and a force of $2000 \mathrm{~N}$ from the top is applied.

\section{ANSYS report on Shaft}

Table 15 Shaft Ansys Notations

\begin{tabular}{|c|c|c|}
\hline S. No & Specifications & Values \\
\hline 1. & Force & $2000 \mathrm{~N}$ \\
\hline 2. & Direction Components & Vector \\
\hline 3. & Load Impact & Top \\
\hline 4. & Analysis & $0.5 \mathrm{~kg}$ \\
\hline 5. & Mass & $2.9749 \mathrm{e}-012 \mathrm{~mm}$ \\
\hline 6. & Centroid X & $-5.7111 \mathrm{e}-012 \mathrm{~mm}$ \\
\hline 7. & Centroid Y & $-7.5307 \mathrm{e}-003 \mathrm{~mm}$ \\
\hline 8. & Centroid Z & $6.9145 \mathrm{e}-004 \mathrm{MPa}$ \\
\hline 9. & Minimum Stress & $26.157 \mathrm{MPa}$ \\
\hline 10. & Maximum Stress \\
\hline
\end{tabular}

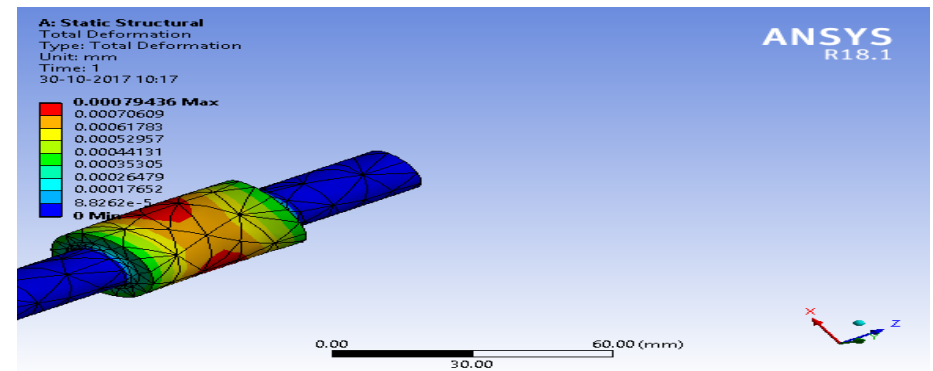

Figure 27 Analyses of Shaft

On the basis of above figure 27 we represents the assembly of shaft is to be fixed by 4 faces as a fixed support and then applying a force of $2000 \mathrm{~N}$ from top. As in resulting portion we find that the Minimum stress $=6.9145 \mathrm{e}-004 \mathrm{MPa}$ and Maximum Stress $=26.157 \mathrm{MPa}$. 
Mechatronics and Applications: An International Journal (MECHATROJ), Vol. 2, No.1

\section{ANSYS report on Drive Wheel}

Table 16 Drive wheel Ansys Notations

\begin{tabular}{|c|c|c|}
\hline S. No & Specifications & Values \\
\hline 1. & Force & $2000 \mathrm{~N}$ \\
\hline 2. & Direction Components & Vector \\
\hline 3. & Load Impact & Top \\
\hline 4. & Analysis & Total Deformation \\
\hline 5. & Mass & $15.25 \mathrm{~kg}$ \\
\hline 6. & Centroid X & $1.0223 \mathrm{e}-014 \mathrm{~mm}$ \\
\hline 7. & Centroid Y & $1.3639 \mathrm{e}-015 \mathrm{~mm}$ \\
\hline 8. & Centroid Z & $-2.4007 \mathrm{e}-015 \mathrm{~mm}$ \\
\hline 9. & Minimum Stress & $5.9911 \mathrm{e}-003 \mathrm{MPa}$ \\
\hline 10. & Maximum Stress & $0.39088 \mathrm{MPa}$ \\
\hline
\end{tabular}

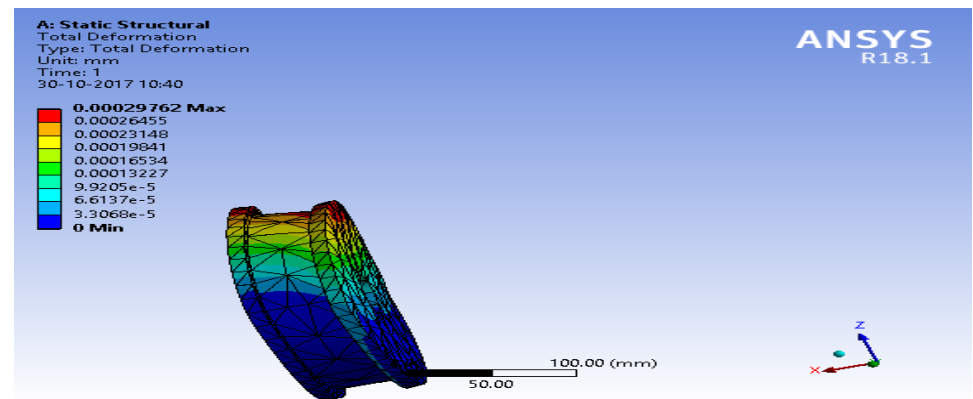

Figure 28 Drive Wheel $1^{\text {st }}$ View analyses

Figure 28 shows the analyses of Drive wheel which is fixed by 5 faces as fixed support and then applying a force of $2000 \mathrm{~N}$ from top which gives us a results as Minimum stress $=5.9911 \mathrm{e}-003 \mathrm{MPa}$ and Maximum Stress $=0.39008 \mathrm{MPa}$.

\section{ANSYS report of Drive Wheel Assembly}

Table 17 Drive wheel Assembly Ansys Notations

\begin{tabular}{|c|l|l|}
\hline S. No & Specifications & Values \\
\hline 1. & Force & $2000 \mathrm{~N}$ \\
\hline 2. & Direction Components & Vector \\
\hline 3. & Load Impact & Top \\
\hline 4. & Analysis & Total Deformation \\
\hline
\end{tabular}

All the above observations represent the overall design of our project. As we noted all above parts are successfully analyses with the help of software using ANSYS.

\section{ACTUAL DESIGN}

After successful design and simulation of our proposed project as discussed in above figures later we went through the actual design. Our actual design fulfills the hypothetical parameters up to $88 \%$ with slight $12 \%$ changes from it which were found necessary in order to successful run of Di-wheel on harsh condition for smooth running. Figure 29 shows the actual design of Di-wheel which was prepared by us on the basis of our previous mathematical parameters and computation simulations. 
Mechatronics and Applications: An International Journal (MECHATROJ), Vol. 2, No.1

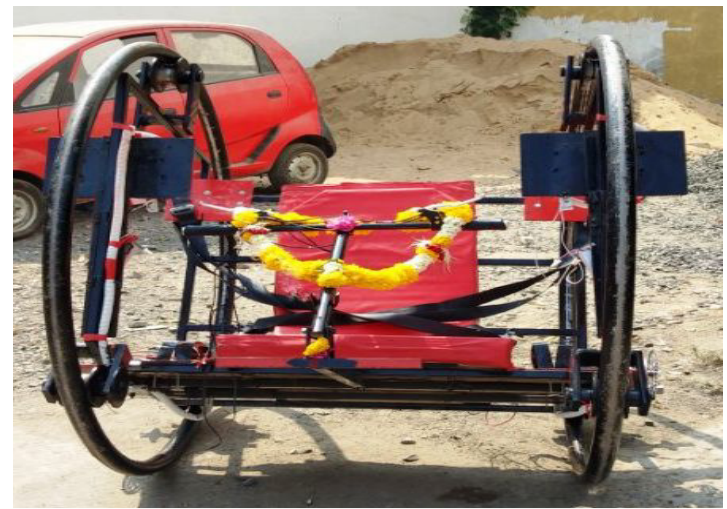

Figure 29(a) Final Assembly View 1

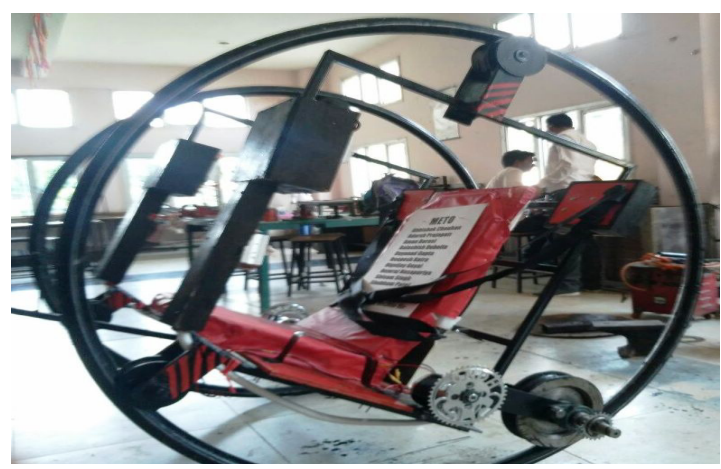

Figure 29(b) Final Assembly View 2

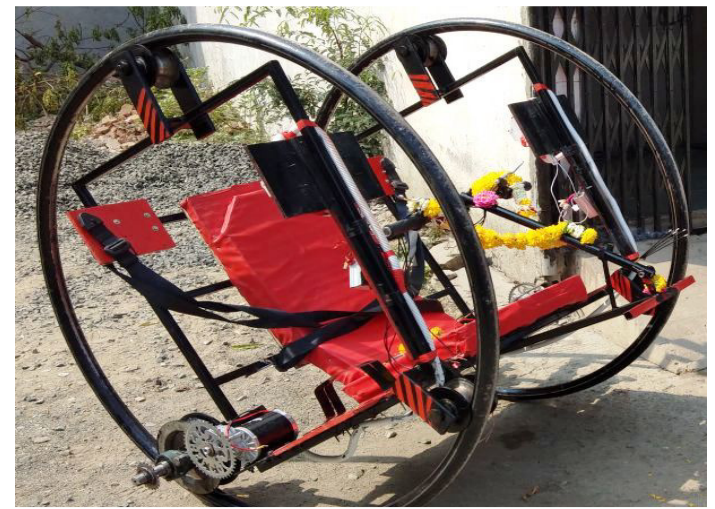

Figure 29(c) Final Assembly View 3

Figure 29 METO - The Di-wheel

\section{* Efficiency}

The points represents various factors with explains that shows effectiveness of our project METO

1. Firstly the very important fact that it can easily carry $130 \mathrm{~kg}$ weight (excluding chassis weight).

2. The value of rated torque is much high of our design.

3. It has being also packed with regenerative breaking system.

4. The Centrifugal \& Centripetal forces are well balanced.

5. We also achieve an effective speed up to $20 \mathrm{Km} / \mathrm{hr}$.

6. The drag force is made bigger then lifts force by aerodynamics study. 


\section{* Ergonomics}

As we all know about ergonomic factors which were important to consider during the design of any human related components. In designing METO, we have also focused on minor hand and legs movements of a human body with completely considered of safety related factors.

1. In addition, to that we have also focused on the brain quick responses to the controlling unit.

2. On the basis of these studies, the cockpit cabin was designed by us in order to provide better control.

3. The handle was designed on the basis of interaction and easy access made for humans.

\section{WORKING PRINCIPLE}

\section{* Basic working principle}

The METO has one basic principle for allowing it to run in forward, reverse \& Spot rotation direction, i.e. the direction of flow of current which is provided to the motor.

\section{Forward Direction}

In, this case the current is allowed to move in similar terminals i.e. not changing the phase of the terminals as a result positive terminal joints positive side of battery and negative terminal joints negative side of battery of both wheels and the vehicle moves in forward direction.

\section{$>$ Reverse Direction}

In, this case the current is allowed to move in reversed terminals i.e. by changing the phase of the terminals as a result positive terminal joints negative side of battery and negative side joints positive side of battery of both wheels and the vehicle moves in reverse direction.

\section{Spot Rotation}

In, this case the current is allowed to move in both same and different direction in two wheels i.e. by changing one phase of the motor of one wheel in reverse direction and leaving another motor of second wheel in forward direction as a result vehicle starts spot rotation.

\section{PROCESS SCHEDULE}

During the entire work of our design we went through different phases for completion. Table 18 shown below gives a fact overview of different steps were considered for the successfully completion of our work.

Table 18 Master production schedule

\begin{tabular}{|c|l|}
\hline S. No & Detail \\
\hline 1. & Production of drive wheel and idler wheel \\
\hline 2. & Accommodation of drive wheel and idler wheel \\
\hline 3. & Production of chassis \\
\hline $\mathbf{4 .}$ & Accommodation of chassis \\
\hline $\mathbf{5 .}$ & Production of outer wheel \\
\hline $\mathbf{6 .}$ & Accommodation of outer wheel \\
\hline $\mathbf{7 .}$ & Production of shaft carrier \\
\hline $\mathbf{8 .}$ & Accommodation of shaft carrier \\
\hline $\mathbf{9 .}$ & Temporary assembly of METO \\
\hline $\mathbf{1 0 .}$ & Accommodation of bearings \\
\hline $\mathbf{1 1}$. & Production of shaft \\
\hline
\end{tabular}


Mechatronics and Applications: An International Journal (MECHATROJ), Vol. 2, No.1

\begin{tabular}{|c|c|}
\hline 12. & Accommodation of shaft \\
\hline 13. & Assembly of METO \\
\hline 14. & Twisting of mechanical Assembly of METO \\
\hline 15. & Lubrication \\
\hline 16. & Evaluation of mechanical assembly of METO \\
\hline 17. & Accommodation of electrical components \\
\hline 18. & Testing working of all electrical components \\
\hline 19. & Evaluation report of all working components \\
\hline 20. & Failure \\
\hline 21. & Correcting failure in electrical component (controller)' \\
\hline 22. & Testing working of electrical component \\
\hline 23. & Evaluation of working components \\
\hline 24. & Temporary seat assembly \\
\hline 25. & Placing electrical component in METO \\
\hline 26. & Completing the electrical circuit design of METO \\
\hline 27. & Testing the working of components in METO \\
\hline 28. & Evaluation of working \\
\hline 29. & Providing chain \& sprocket to the METO \\
\hline 30. & Testing the working of chain and sprocket \\
\hline 31. & Paint job in production \\
\hline 32. & Paint job completed \\
\hline 33. & Complete seat assembly \\
\hline 34. & Testing comfort of seat \\
\hline 35. & Evaluation of seat assembly \\
\hline 36. & Seat belt installation \\
\hline 37. & Seat belt response test \\
\hline 38. & Evaluation of response test \\
\hline 39. & METO goes for first phase testing (weight bearing capacity test) \\
\hline 40. & Evaluation of first phase test. \\
\hline 41. & METO goes for second phase test (inclination test) \\
\hline 42. & Evaluation of second phase test. \\
\hline 43. & METO goes for third phase test variable condition $\{$ day $\&$ night $\}$ test $).$ \\
\hline 44. & Evaluation of third phase test. \\
\hline 45. & Final testing on a designed circuit \\
\hline 46. & Final evaluation report. \\
\hline
\end{tabular}

\section{* Process used description}

\section{$>$ Electric welding work $[10]$}

Arc welding is a process that is used to join metal to metal by using electricity to create enough heat to melt metal and then the melted metals when cool result in a binding of the metals.

\section{$>$ Gas metal arc welding work (GMAW) [11]}

It is commonly called MIG it is a semi-automatic or automatic welding process with a continuously fed consumable wire acting as both electrode and filler metal, along with an inert or semi-inert shielding gas flowed around the wire to protect the weld site from contamination. We used electric welding for joining/welding the chassis joints in order to create frame and a stronger structural bind which can bear heavy load in harsh conditions.

\section{$>$ Gas welding work [11]}

1. Oxy-fuel welding and oxy-fuel cutting are processes that use fuel gases and oxygen to weld and cut metals, respectively.

2. Oxy-fuel is one of the oldest welding processes, besides forge welding.

3. In oxy-fuel cutting, a torch is used to heat metal to its kindling temperature.

4. We, used gas welding in our project in order to create specific large holes which doesn't need precision or high accuracy for saving time without dealing with strength loss. 
Mechatronics and Applications: An International Journal (MECHATROJ), Vol. 2, No.1

$>$ Shaper Machine work [12]

1. A shaper is a type of machine tool that uses linear relative motion between the work piece and a single-point cutting tool to machine a linear tool path.

2. We used shaper machine for cutting out slots and special holes for nut fitting and in addition to that we also used shaper machine for the making of key slot and keys for the shaft \& the drive wheel in order to provide locking for a better transmission of power.

\section{Grinding Machine work [13]}

Grinding is an abrasive machining process that uses a grinding wheel as the cutting tool. In our METO, following grinders were used for removing of abrasive materials and other operations.

- Angle grinder, a handheld power tool

- Bench grinder, a bench top power tool

- Cylindrical grinder, a machine tool for precise grinding of cylindrical parts

- Center less grinder, a machine tool for precise center less grinding

- Surface grinder, a machine tool for precise surface grinding, mostly of flat planes

- Tool and cutter grinder, a machine used to manufacture or reshape cutting tools

\section{$>$ Milling machine work [14]}

Milling is the machining process of using rotary cutters to remove material from a work piece by advancing the cutter into the work piece at a certain direction. The cutter may also be held at an angle relative to the axis of the tool. We used this milling machine in our METO, for the processing of the shaft carrier for smooth finish and shaft abrasion near sprocket fixation.

$>$ Cutting machine work [13]

The cutting process was used in our METO, for cutting out the extra length of the frame material and also the extra length of the shaft carrier and the extra length of screws.

\section{$>$ Drill Machine work [14]}

The drill work was very actively used in our METO, for providing small \& medium size holes for screws at certain area in plywood and metal for proper positioning of appliances of METO.

\section{$>$ Hydraulic Press Work [15]}

A hydraulic press is a device using a hydraulic cylinder to generate a compressive force. We used the hydraulic press for the linear level measured with the help of the spirit level for providing a good leveling to the shaft carrier to meet the maximum accuracy.

\section{Pipe bending work [16]}

Roll bending is the process in which the pipe, extrusion, or solid is passed through a series of rollers which apply pressure to the pipe gradually changing the bend radius in the pipe. In our METO, we used three-roll push bending for the bending of the outer wheel which is 2 inches thick and $20 \mathrm{ft}$ in length for making it in $5 \mathrm{ft}$ diameter circle without threads in the iron.

1. Three-roll push bending

2. Three-roll push bending process

\section{$>$ Lathe machine work [17]}

A Machine that rotates the work piece about an axis of rotation to perform various operations such as cutting, sanding, knurling, drilling, deformation, facing, and turning, with tools that are applied to the work piece to create an object with symmetry about that axis.

We used lathe machine in our METO, in the processing of cutting circular shapes for shaft in the shaft carrier and the processing of drive wheel for iron circular bars and also the idler wheel production processing was being done on lathe machine. In thus way lathe machine played a very vital role in our METO, as it is being used may times in many other operations too. 
Mechatronics and Applications: An International Journal (MECHATROJ), Vol. 2, No.1

\section{Conclusion}

As on the basis of Di-wheel project we have completed the design procedure in 2D and 3D by making the whole chassis design. The whole drafting was completely done by using Creo software and Ansys workbench is used for analysis purpose. In sheet drafting and computational work we provide the parameter in different situation and these parameters will be same for calculation also. After the design procedure of Creo we analyze the design by Ansys software by meshing the design.

Analysis was done by taking equivalent stress and total deformation for our main calculation. The whole work and design was mathematically and computationally validated by us. We perform all the mathematical terminology for chassis, wheels, steering, frames and battery portion. We also calculate the power and working capacity of battery us per the working performance.

The final mathematical and computation design and real design validated successfully with each other.

As for the part of Future scope Now, talking about design there are numerous changes we can make in order to increase its efficiency like

1. Providing hub motor, in order to decrease weight and increasing power output.

2. Suspension for better traction control (optional).

3. Better harness system.

4. More better controlling unit.

\section{REFERENCES}

[1] Jonathan Atternot, Benjamin Devis, Samuel Hart, Erin Pearce, Electric Di-wheel with active damping rotations. The University of Adelaid 2011

[2] Pawel Piejko. EDWARD-a diwheel student- built vehicle that really works, The University of Adelaid 2011

[3] B. Cazzolato, J. Harvey, C. Dyre, K. Fulton, E. Schumann, T. Zhu, Z. Prime. Control of an electric diwheel, University of Adelaide, Australia 2009

[4] J.Parsons, B.Cazzolato, L.Francou, Z.Prime, Fully coupled dynamics of an electric Di-wheel, JSME technical journal 2017: Volume 1, Issue 1.

[5] S. J. Aliabadi, A. Johnson, J. Abedi, Comparison of finite element and pendulum models for simulation of sloshing. Computers and Fluids 2003: Volume 32, Issue 04.

[6] FL Bearing, Google Images 2018: Available From: -

URL: -

https://www.google.com/search?client=firefox-b-

ab\&biw $=1366 \&$ bih $=654 \& \mathrm{tbm}=\mathrm{isch} \& \mathrm{sa}=1 \& \mathrm{ei}=$ pfgUW8CDGYPYvATX2ZLgBQ \&q=FL+Bearing\&o $\mathrm{q}=\mathrm{FL}+$ Bearing\&gs_l$=\mathrm{img} .3 \ldots 2529.3959 .0 .4693 .9 .8 .0 .0 .0 .0 .0 .0 . .0 .0 \ldots .0 . .11$. $1.64 . i m g . .9 .0 .0 \ldots . .0 .1 \mathrm{pMy}$ ADHXA1A

[7] SKF, Deep Grove ball bearings, Dimensions 2018

[8] Physics tutorials, The physics classrooms 2018

[9] ROBU.IN, E bike MY1020Z 600W 36V 3200RPM DC Motor (GB) 2018

[10] Jay Leone, Type of Electric Welding, SCIENCING 2017

[11] Admin, Gas Welding: Principle, Working, Equipment, Application, Advantages and Disadvantages, mech4study 2017

[12] Admin, Principal and working of shaper machine, Engineering tutorials 2009Yash Shah, Type and use of Grinding machine, Bhavya 2012

[13] E.Vijaya Kumar, Design and Analysis of Rotor Shaft Assembly of Hammer Mill Crusher. IJEMR 2013: Volume 03 Issue 02.

[14] Manufacturing Technology, Milling machine definition, process and types, Engineering Articles 2015

[15] Joseph Camerata, Hydraulic Principles course, ABCTLC 2018: ISBN 978-0-9799559-8-3

[16] Admin, Pipe and tube bending process, Thomas 2018

[17] Vikash Shukla, Lathe machine: Main part, operation, and work, Engineering Insider 2017: Available 